\title{
Patterns of transition zone between Eurasian and North American plates (by example of stressed state of the Sakhalin Island)
}
L. A. $\operatorname{Sim}^{1}$
G. V. Bryantseva ${ }^{2}$
P. A. Savvichev ${ }^{1}$
P. A. Kamenev ${ }^{3}$

\author{
${ }^{1}$ Institute of Physics of the Earth, RAS, Moscow, Russia \\ ${ }^{2}$ Lomonosov Moscow State University, Moscow, Russia \\ ${ }^{3}$ Institute of Marine Geology and Geophysics, FEB RAS, \\ Yuzhno-Sakhalinsk, Russia
}

\begin{abstract}
The study of neotectonics, neotectonic and modern stress of the Sakhalin have been performed by complexity of methods. The scheme of modern Geogynamics of the island has been built by the data of neotectonic activation of the faults. Three types of zones have been distinguished: zones of faults origination under conditions of tension, compression and triaxial stress conditions. The results of Sakhalin modern stress reconstruction based on focal mechanisms of earthquakes allowed to characterize the distribution of the stress state parameters over the island surface, such as axes of deviatoric compression and tension, LodeNadai factor, modern geodynamics regime, and modern shear stress on crust and mantle boundary. The changes in characteristics of modern tectonic stress field were founded at the boundary regions of different regime of modern faulting. Specific orientation of compression axes of neotectonic stress field is proper for North Sakhalin (north east direction of compression on the background of sublatitude orientation on the rest island). The results of the research contradict to the opinion that the border between Okhotsk and Amur microplates in southern part of the Sakhalin is located nearly zone of Cenrtral Sakhalin Fault.
\end{abstract}

\section{Keywords}

Amur and Okhotsk microplates, Neotectonics, Neotectonic and modern stress, Focal mechanisms of earthquakes

\section{References}

For citation: Sim L.A., Bryantseva G.V., Savvichev P.A., Kamenev P.A. Patterns of transition zone between Eurasian and North American plates (by example of stressed state of the Sakhalin Island). Geosystems of Transition Zones, 2017, vol. 1, N 1, p. 3-22. doi:10.30730/2541-8912.2017.1.1.003-022 